\title{
OPEN
}

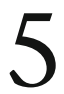

\section{Translating the Humanities}

This chapter explores the different ways in which research's insights and results are communicated and translated to beyond university boundaries. First we outline the flow of academic knowledge from researcher to end user. Second, we look into how this translation takes place, according to current national reports, and identify what senior academic researchers and academics in leading positions believe is happening and what they recommend. We find that the knowledge pool of the humanities is tapped in haphazard and entirely contingent ways. The way forward is to ensure that translational practices are valued and resourced adequately. The flip side of that coin is that problems of academic freedom and ethics must be addressed.

\section{Translational research practices}

Knowledge, insights and findings are the outcome of research but they need to be communicated to and internalised by recipients before they can be of value outside the researcher's mind. Teaching, publishing, broadcasting, lecturing, engaging with communities, putting knowledge into practice in public institutions, medical care, schools, business, advising on policy and so on are all examples of communication. They may be captured by the concept of knowledge transfer. In many types of research, however, knowledge flows in more than one direction: as the researcher engages with a field, he or she learns from the practitioners; the people who are the object of the research may engage with the researcher and share their insights; practitioners may also criticise and help refine research insights as they are shared or published. In broad terms, these loop-back mechanisms may be defined as knowledge exchange. Knowledge flows may be supported or stimulated by 
knowledge infrastructure, such as museums and galleries, and best practice as generally accepted by researchers or prescribed by senior academic management or contractually agreed with third parties. Utlimately, decisions to fund or initiate research may be informed by a consideration of the communicability of that research or by end user needs. Such considerations may, for example, inform the research strategy of a museum or an independent research organisation. They may also inform requests for research by funding agencies, either through the prioritisation of a particular theme or by requesting solutions to a particular problem.

To capture the full extent of such knowledge flows we use the concept of translational research practice as a broad term for the flow of research insights from a researcher or a group of researchers to a broader community of other researchers and end users, and the feedback processes that come with the interaction.

The concept of translational research is broader than the more commonly used term transactional research, which we define as the commitment of researchers to bring knowledge into social action, and is therefore a specific form of what we would identify as the role of the public intellectual. Transactional practice is well known from certain types of sociological work, which involves direct interaction with a community to empower a decision process. While transactional practice is certainly part of translational practice, the translational concept is broader since it includes the infrastructural, institutional and funding parameters of research. The translational concept also includes research practices, which are not dedicated to any type of direct intervention. Translational research practice is therefore a concept that is relevant to all of the humanities as regards the flow between the production of research and its appropriation.

All research translation needs to happen through specific channels, and those channels may select what is good and relevant research and therefore ultimately decide what gets funded. Translation channels in the humanities typically involve:

- Academic publication

- Public intellectual practice

- communication to the public via the media (popular books, web, TV, lectures)

- personal interaction with communities, stakeholders and policy makers

- Contractual engagement with public institutions, e.g. schools, museums, archives, public bodies and professional associations

- Entrepreneurial engagement with innovation systems and businesses. 
Inherently, there are very real dilemmas and blocks in the flow from academic research to translational practice. Much academic research is driven by the individual curiosity of the academic and translation may generate a clash with outside requests. While academic publishers have streamlined, if not perfected, the production of books and papers, in most other walks of life academics in general and humanists in particular find that translation involves considerable costs in both time and presentation of research output. Indeed, the use of knowledge may potentially compromise the integrity of the academic and there are therefore ethical choices to be made and economic costs involved in translational practices.

Finally, considerations and choices of translational research practice may involve a prescriptive element. So far, we have used the term exclusively in a descriptive way but research managers (dean, departmental chair or the director of an academic unit such as a museum or private company) may prescribe certain translation practices as part of a strategy to optimise the use and impact of research output. Such prescriptive strategies may be based on academic consensus as, for example, some disciplines adhere to a notion of best practice for community feedback or they may be based on a common sense approach to the need to project the voice of the humanities. In recent years, many universities have established humanities institutes and centres to facilitate research, to promote public interest in and to project the relevance of the humanities. Many thematic research centres are similarly established with both a translational and a research agenda.

While a prescribed strategy of translation would be alien to many academic institutions, it is known to come up - often as a surprise when large financial considerations are at stake. Less controversially, such concerns may also inform or influence individual academic choice at the start of a research project. Many, if not most, humanities projects begin from a need for a better product than the one at hand, such as a critical edition of a manuscript or a need to understand better how society worked in the past. Translational concerns about the end product are likely to inform the design of such projects, for instance when a digital humanist designs a user-friendly interface that allows for multiple layers and feedback. Similarly, new findings or changes to the research agenda often cause the researcher to rethink modes of translation.

\section{Translational medicine}

By way of contrast it may be useful to consider translational practices in academic fields outside the humanities. Translational medicine is a 
term that was increasingly used from the late 1990s to denote - and promote - a transformation of health research through an emphasis on shortening the turnover time and reducing transaction costs 'from bench to bedside' or from bioscience laboratory to clinical practice. Translational medicine is key to the strategy of major funding bodies, such as the American NIH and the British MRC, to ensure that basic research and knowledge at one specialised level is translated to the next, and to develop collaboration from research labs to hospitals, GPs and ultimately to patients. Crucially, this is identified as a bi-directional strategy and so inherently prescribes collaboration between researchers and practitioners. Translational research practices require dedicated institutional support structures and funding models, including entrepreneurship and business. ${ }^{1}$ This is clearly expressed in this quotation:

The ultimate question regarding any biomedical research is whether it addresses a real need (of patients, people or populations) and helps improve people's lives (by preventing, curing, or improving the outcome of disease). To facilitate the 'translation' of new knowledge into health benefits, the scientific community, healthcare providers, industry, policymakers and the community at large need to apply their collective capabilities in a highly collaborative manner, across disciplinary boundaries. ${ }^{2}$

As a strategic concept, translational medicine is not just an analytical tool used to observe actual research practice, it is also a form of rhetorical discourse or an instruction with a view to a particular goal, viz. promoting the flow of knowledge from bench to bedside. ${ }^{3}$ The concept also makes clear that parameters outside pure science determine the impact of the findings: "The success of translation does not lie with scientists, however good their science, but with human motives, individual and corporate, selfish and unselfish, which underpin health care markets and drive market traders' ${ }^{4}$

These observations may help understand translational research practices in and recommendations for the humanities. Of course, the humanities differ from the health sciences with regard to justification and outcome of research. Knowledge gained in the humanities may have consequences for life and death (for instance, through improved methods of peace negotiations; smart sanctions; social reconciliation after conflicts). However, in medical science the significance is more direct, at least more directly felt, and, humanities scholars disagree about justification, as we saw in Chapter 2. Obviously, the choice of 
translational strategy depends on the aim. Translational practices will therefore vary greatly between, say, an American liberal arts tradition and a practice that focuses on implementation of research findings.

However, the problems of translation within humanities do resemble those within contemporary biomedicine as they ultimately revolve around human linkages, institutional practices and intertwined communities. The humanities are just as conditioned by the interaction of researchers and practitioners whose training, outlook and institutional context vary greatly. ${ }^{5}$ Social learning may be important for the choice of research fields and methods and, indeed, ideological and social pressures can have very negative effects. These are well-known problems but it may be helpful to conceptualise them not as problems peculiar to the humanities but as part of a general translational problem for academic research.

\section{Evidence from interviews}

In the following section we look at how senior academics responded individually and in workshops to our questions about humanistic practices of translation. The interview questions were:

How are you or members of your organisation working with or exchanging knowledge with stakeholders outside academia?

What support systems are in place for translational research?

The interviewee was encouraged to expand and qualify their statements as they wished. The questions are quite open and respondents therefore gave evidence in accordance with their interpretation of the questions. In the regional workshops we were able to follow up on the interviews to get a more consolidated view from participants.

\section{Quantitative evidence}

Table 5.1 summarises respondents' experience of and commitment to translational practices. A total of 26 gave very low or negative priority to the questions: 18 did not give a response; three declared they did not understand the question; only five expressed a negative or cautionary attitude to the idea that a university should concern itself about outreach. On the other hand, a clear majority of 62 people gave positive examples of translational practice. Their responses may be categorised at the individual, collegial and partnership levels, and some gave examples of 
all: 46 provided examples of personal experience; 16 offered examples of collaborative efforts; and 42 stressed the importance of non-university partnerships.

There were some clear regional patterns among the interviewees. European, Australian and Asian respondents stressed the importance of non-university partnerships, while African, Latin American and North American respondents gave examples of personal commitment. Out of 16 European interviewees 12 stressed the importance of non-university partnerships, while six mentioned personal experience and only two gave examples of collaborative efforts with colleagues. Only four Asian respondents gave examples of personal experience, while nine gave examples of non-university partnerships, such as with galleries and media. On the other hand, individual engagement was cited the most in Latin America (7 out of 9), Africa (10 out of 13), and North America (14 out of 16). These differences may reflect institutional cultures as well as the lack of institutional partners in some regions. In light of the importance that European funding agencies attach to questions of public impact it is striking that so few examples of personal engagement were forthcoming from European respondents. In general, however, the interviews gave a strong sense that humanists are committed to translating their research and many cite positive experiences of such engagement.

Responses at university level are similarly summarised in Table 5.2. No fewer than 49 respondents offered no opinion on their university's dedication or lack thereof, while 24 noted strong institutional support for translational practices, ten noted institutional indifference, and only three felt that the university actively discouraged researchers from engaging in translation.

A total of 11 out of 16 North Americans confirmed that there is institutional support for translational practice, while only 17 of the

Table 5.1 Translational practices among respondents

\begin{tabular}{lr}
\hline Did not respond to question & 18 \\
Did not understand question & 3 \\
Negative or cautionary remarks & 5 \\
Positive evidence & 62 \\
- individual commitment & 47 \\
- collegial efforts & 16 \\
- non-university partnerships & 42 \\
\hline
\end{tabular}


Table 5.2 Respondent views on universities and translational practices

\begin{tabular}{lr}
\hline & 46 \\
\hline Institutional commitment & 28 \\
Institutional neutrality & 12 \\
Institutional discouragement & 3 \\
\hline
\end{tabular}

72 respondents from other continents were affirmative. This pattern probably reflects the strong role of humanities centres in the US and Canada and a strong culture of institutional engagement with alumni and communities.

In general, it may be fair to say that the figures indicate that most respondents, especially outside North America, believed that their own university offered very little support for translational activities. Respondents were divided between a majority with individual experience of translational practice, and a minority who gave little weight to such practice. The interviews give evidence of a richness of experience and a variety of concrete engagement. The following examples, by necessity, draw more on interviewees who expressed a positive interest.

\section{Educating role}

Undergraduate teaching is explicitly excluded from this report and was therefore not identified in the interviews as a translational practice. Most interviewees identified the translational role of the humanities as one of educating and reaching out to the public by means of open lectures. Open lectures can be standalone events or serialised, sometimes building up to a coherent programme from several months to a full year. One director of a humanities institute (E9) was clear that public engagement was a core activity. Similarly, a dean at the same university stated that

(E11) Knowledge exchange and public engagement is an enormous issue for us. We have a college knowledge exchange office and manager and every school has an officer engaged in supporting knowledge exchange and - we hope - also a part of its research office dedicated to that work. 
The director of a specialised research institute expressed the same opinion:

(E2) The... Centre sees itself as a public resource and forum for all issues that have to do with [our field]. We offer many lectures that are open to the general public; we interact with the media and contribute to non-scholarly publications (magazines, weeklies) as often as possible. I have written books for general readers; I participate in teacher training and give public lectures.

Similar views were expressed by the director of a Latin American research centre, LA2: 'Translation is very important to my field and in my university. [My university] takes a big stand on the popularisation of research.' From Asia, As1 stated that public lectures and seminars were a key component of the centre for advanced studies at his university.

However, many stated that support for even such basic outreach activities was undeveloped,:

(As12) Support systems for translational research are still very limited. There has been no national support for institutions for translations or translational research.

That interviewee personally took a leading role in developing projects with local museums nationwide. Some interviewees with no management role subscribed to the same opinion. A professor from Australia wanted see public outreach developed even more:

(Au1) There's not enough of this in Australia. A lot depends on your field: the fine arts do work well with galleries and museums, well, as do local historians to an extent. But international historians are less 'out there' (except on radio and occasionally TV). And there's not much in the way of support systems for outreach.

Some European voices echoed this sentiment. E3 reported that the university had no funds or policies for translation practice, and another lamented the underdeveloped state of translation:

(E6) This is certainly an underdeveloped field. The transmission of insights from research is often indirect and invisible as such, as e.g. when members of our faculty writes newspaper reviews of books, 
plays, art exhibitions etc. Other and more visible examples are cooperation between historians and local communities on writing local history, or cooperation between linguists and local communities on local place names, often funded by the local community. There are no permanent support systems in place for this kind of community related research.

Finally, African humanities are particularly deprived of support structures. One African interviewee, Af5, said that 'there is not any support for translational research that I know of. Anything done along this line is born from one's own initiative and commitment'.

As we shall see below, the evidence of the interviews indicates that direct community involvement rather than public lectures are preferred by many African scholars. It should be noted though that South Africa has excellent support for elite universities, including new humanities centres.

Several interviewees mentioned the particular importance of outreach to secondary level teachers. They will often be graduates themselves, have a special interest in university research, and want to convey the newest ideas to their students. One professor stated:

(E15) In my field translation mainly happens in three ways. (1) The university classicists keep in touch with 'real life' through high school teachers by keeping them in touch with their research. This happens via conferences both biennially on the national level (with 1,000 and more participants), and much more often regionally and locally. (2) There is clearly a market for publications written by specialists for a wider public. The format of these publications ranges from relatively voluminous books (often with lavish illustrations) to small booklets which inform concisely (circa 100 pages) on a specific topic (as in the series Wissen of the Beckverlag). (3) There are the Volkshochschulen (programmes of adult education) sponsored by individual cities, providing evening classes on a wide range of topics including those concerned with classics, as Latin, Greek philosophy, Roman Germany or whatever.

A similar broad range of outreach activities was identified by E8. He gave as examples a foreign language summer school, public performances of folksongs to maintain their presence, a folksong competition in an island community, public lectures, public readings and media consultations. A Russian interviewee, R5, similarly identified workshops 
for teachers, journalists, and museum researchers as a regular outreach activity.

Interviewee E1 indicated some frustration at the limited extent to which the humanities have developed translation as the third task of the university, after teaching and research. The humanities have "not really [developed] in the same way as economics or medicine. In the end, it ends up with third task examples that you tell the public about'. However, many interviewees did give examples of humanities going beyond public lectures.

\section{Community engagement}

While African universities generally suffer from lack of infrastructural support, the interviews did give striking evidence of individual engagement. One professor listed a number of vibrant health research projects, including in the behavioural sciences, that involved working with and learning from local communities.

(Af3)... we teach, train, and undertake research with local communities as we address their primary health needs. Translational research is supported through the office of the deputy vice chancellor in charge of research and extension, through annual conferences, and through community engagement and outreach work. There haven't to date been specific humanities knowledge exchange programmes, but [the university is] increasingly seeking to develop these as they continue to review their programmes. In [the interviewee's department] for example, there is a programme on youth and development where students work with young people in the community.

Another interviewee stated:

(Af5) in my case I often organise information-sharing rallies at my research sites close to the conclusion of my research where I inform them of what I have found and what that means in terms of science. Thereafter, I make publications in simple language and take them back to them. Finally, all tangible materials retrieved from the field work are submitted to the Antiquities Department as required by law. Some of these may end up in museums. In addition to these basic steps, feature articles in local magazines, commentaries on radio and TV, etc. are used. This is done by most researchers, archaeologists and non-archaeologists. 
Af7 stated:

In the recent past the University of Zambia has introduced a public forum at which stakeholders, including government, are invited to public displays and dissemination of research work. This process is expected to open avenues for translating both humanities and science researches into end user products.

The interviewee also stated that a regular methodology was the practice of going back to communities where fieldwork was conducted and reporting results to them as producers of the primary data.

However, most African interviewees noted an absence of support for any kind of translational practice. Af1 stated:

down here 'social impact' does not amount to much since the arcane findings of our research are only valued in obscure foreign journals especially if the research contains a title no one really understands! The government could not be bothered - despite [country] having numerous research institutes.

Af2 noted that translational activity is patchy in Africa:

it happens if it's part of funding requirements, or if an individual researcher happens to think it's important for them to take their research back to the community. The support systems are also patchy, though there are some institutions who have a history of taking research beyond the usual academic boundaries.

A more optimistic note was expressed by Af13:

Cultural production has also been an important site of experimentation with new ideas and indeed understanding the continued transnational dialogue that has been going on in this continent for generations. I think this dialogue has contributed to what now passes as a common human culture and the ideals of a common humanity that we are all striving for.

Community engagement is typical of much anthropological, archaeological and even historical work. One historian, As15, stated that, after publication of a dissertation as a monograph, engagement with the 
community has continued, and indeed one monk 'now uses my book to train young monks'. Similarly, a Brazilian archaeologist reports:

(LA2) We're engaged in 'public archaeology', where the focus is on work with the community (e.g. through museums). To give an example. We worked with a community of Indians in the Amazon Basin. We studied artefacts from the region, but then donated them to the Indians and also had a dialogue in which we exchanged our different interpretations of the objects.

A different take on community engagement was noted by As14, who reported that the university provided free public music concerts and

will send scholars or students to villages and towns, especially aboriginal villages. They'll talk to people about general problems and they'll speak to students to get them excited about the issues in the humanities and sciences.

Many North American humanities centres have extensive community involvement. NA9 reported that the centre

has exhibitions, public readings, poetry readings all the time. We are really engaged and very active in the community. I'm atypical, I would say. But remember that this isn't just a place for literature, we have a very good collection of photography and film. Public engagement is in the mission statement of the $[. .$.$] Centre.$

\section{NA10 stressed that}

our humanities institute has always put a lot of emphasis on the public humanities, on building bridges between the public and the university, on recognising the kind of thinking that is going on in the public. So, rather than a knowledge transfer or translation model, it's a more synergistic model. And there is absolutely not enough support for this work because of the recent downsizing. That's true, I think across the board. This kind of work is categorised under service and it's seen as supplementary rather than as basic.

By contrast, community engagement was not mentioned by European interviewees with the exception of E10 who stated that 'historians and researchers of literature rarely meet stakeholders of the university, while 
it is more common in fields such as sociology and psychology'. The focus of European respondents was much more on institutional partnerships, as we shall see below.

\section{Social media}

Social media, such as Twitter, YouTube, blogs, LinkedIn, academia. edu and Facebook, are increasingly used by individual academics. For instance, one of our African respondents maintained a blog linked to a number of social media:

(Af1) I am engaged in community work dealing with the digital preservation of Arabic manuscripts, musical performances and the film industry. I have a website and a production company (visually ethnographic, part of the website). I use these platforms to interact with the community of writers, local scholars, practitioners to find ways of improving practices at all levels.

A similar use of social media was reported by one of our Indian respondents (As5). Research centres are also increasingly using social media, as reported by an American interviewee (NA1), whose centre, in addition to live streaming public lectures, uses social media to create attention. Another American (NA6) had started a research project to showcase humanities research, building on digital resources.

The use of social media for academic purposes is seen as both critical and contentious in Russia where the use of Facebook has become an important tool, not least for academics living in provincial Russia. Often, the success of academics seems measured by the number of public interviews and their visibility in social media. This was confirmed at our Russian workshop as well as in individual interviews. While one respondent (R6) maintained his own blog, he warned against the dangers of overgeneralisation/oversimplification when using fast electronic media. In general, however, he believed that most academics have little time for social media. This sentiment was shared by another Russian (R8) who felt that 'research suffers from overtranslation and media misuse as salon science'.

Although the use of social media for academic work is under-researched, it is conceivable that it provides a fast and much more personal way to engage with user communities and build support for particular research. But it also carries opportunity costs in terms of sacrificing research time. Conventional publicity should still remain pivotal in academia. 


\section{Engagement with media}

The role of intellectuals in media was mentioned primarily in the interviews with Asian scholars. One respondent (As8) mentioned that one of the key performance indicators of Japanese universities is 'the frequency at which scholars talk to the media'. At our East Asian workshop, another Japanese scholar reported that his institute was under too much pressure to disseminate research rather than to facilitate new research.

The interviewees indicated that the role of academics on Chinese and Taiwanese TV is very different. Interaction with mass media may take on quite innovative forms in Taiwan, such as the development of animated cartoons to convey philosophical points. This experiment has been successful and did not lead to oversimplification (As14). However, with the growth of private TV and radio in these countries academics have been cast as entertainers and the level of public discourse in these media is often so low that 'they think of professors that engage with media as a bad thing'. A professor from China corroborated this statement:

(As10) There is not much translation here. When it is done, it's done by scholars who aren't so good. The good ones stay away from it. [My university], which is a top university, does not encourage it, but universities of lesser rank do, especially through TV and newspapers. But scholars who do this kind of thing tend to get looked down on.

But a scholar from Taiwan took a more conciliatory view:

(As14) In my country there's a strong tradition of scholars writing articles in the newspapers and magazines, even appearing on television talk shows. Literature professors, history professors and even philosophy professors look at some current issues and current problems in society through the lenses of their humanities study. I think that if people watch these shows then they do get some impression or they do feel moved by the insights of these professors. It's just that nowadays there is cable television and there's the Internet, so it's much harder for anyone to make a strong impact through one channel anymore. In the old the days there were only three television stations and no Internet so if the professors came on the air they could reach several million people. But now there's too much sensationalism in the media presentations. The reality shows distract people from the reality of what is going on in society and the world.

In the East Asia workshop it appeared that there has been a rediscovery of the humanities in South Korea over the last few years. There are 
public lectures and companies have new employee orientation sessions with lectures demonstrating how creativity and innovation come from the humanities. The view promoted in the workshop was that in South Korea humanities are better represented than in the US.

\section{Political role}

A number of interviewees, nearly all from Latin America and the MENA region, took a very different position. They often stressed the political role of the humanities, whether potential or actual. Seven out of nine Latin Americans gave examples of involvement with political processes, like LA3 who stated that the university

has had a considerable impact on Peruvian society; at a certain point, we got used to taking institutional and public stands on fundamental aspects of our national life. The group of academics and intellectuals that were a part of the Truth Commission - which investigated the crimes and violations of the period of the Shining Path, a terrorist group that unleashed a civil war in the 80s and part of the 90s - has been extremely important in that respect. Our professors continue to comment in the media, taking positions on various themes that affect our country. This has generated strong criticism from the most conservative sectors in our society, and it has even reached the point of open conflict with [the most conservative] sectors of the church. [...] Also, some members of our community participated in the construction and implementation of what is called the Museum of Memory, which remembers the victims of [the civil] war and documents the human rights violations committed by the [Shining Path] terrorist group and also by the [Peruvian governmental] armed forces.

In the same vein, LA4 from Brazil gave examples of direct engagement with the political process of developing a new law on migration and collaboration with artists on an exhibition on human rights. Our Latin American workshop gave evidence of this political role, which is further discussed in Chapter 8.

In Turkey, ME2 identified a similar critical role for the university, and the humanities in particular, and specifically mentions a 2005 conference:

which was organised with a conscious political agenda. And we did have an effect; you can now talk of the Armenian genocide, without using the word 'alleged' in front of it. This is an example of very wide social outreach. At another level, you can reach out to people with 
popular history books. But you need to distinguish between those who draw attention to a particular issue on the basis of little historical knowledge and scholars who maintain the ethical and methodological standards of their discipline while still popularising their subject. We do this to an extent, but not as much as we should. But in Turkey the nationalist culture (i.e. the nationalist reconstruction of history) is a problem: what people read is what confirms their beliefs. We need to do more to break the comfort zone of popularism. Instead we have a tendency to preach to the choir. [...] Among my peers, very few have tried to change the way history is taught in high schools.

Asked about the role of humanities ME4 saw a potential policy role for them:

In Tunisia, the humanities and social sciences are not used in policy making (as is agricultural science, for example). The humanities are actually disturbing to policy makers. So there are almost no links between social demands and SSH researchers; very few get commissioned to work on social policy. But linguists can help in policy, and elsewhere there are links with policy makers, e.g. the use of applied linguistics in educational policy, or in language policy in the context of immigration (which has happened in Holland and the UK).

Such use of linguistics for language policy is also mentioned by As12 for Mongolia and ME3 affirms his engagement:

Yes, I am engaged in outreach. My main link is with regions beyond Lebanon. For instance, as a result of my research on global poverty I work with NGOs in Africa. More generally, in areas like secularism, liberalism and gender equality, research that has been discussed within academia is now having an impact beyond it. In the Arab region, we're now in a moment of reshaping, and ideas that have been for a long time discussed in the humanities are beginning to have an impact. The best example is in Tunisia, where there is a much more mature level of discussion than elsewhere in the Arab world.

It is by no means easy to take this position in all Arab countries as evidenced by ME1:

We need to define who the stakeholders are. As regards policy makers, there's no communication between them and SSH researchers in Jordan. So it's very difficult for researchers to have any influence 
here. To do so, you need to use traditional strategies, i.e. tribal and personal connections. Concerning society itself, it's not easy either. The problem is that Jordanian people read very little. So, like other Jordanian researchers, I publish in Western countries. In fact, although I receive an invitation from overseas every six months or so, I never get one in Jordan. Reading is just not a habit here. However, I have been invited to talk on Jordanian TV. Also, one thing I'm proud of is a project I did with school pupils (ages 12-16). This concerned increasing their understanding of an archaeological site in north Jordan of which the local people were unaware.

Russian interviewees indicated that humanities topics, while generally considered non-political, may be drawn into public debate and indeed raise political concern and even cause political intervention. R2 stated that 'the topic of religion in its connection with history and national identity is too sensitive for Russian society today' and therefore prefers to keep research away from public attention. A particular trait of some leading Russian universities is that they host think tanks to apply research on policy issues (R7). Our Russian workshop confirmed that there is a tension between academic independence and authoritarian interventions, which is especially evident when universities compete for government funding. Special think tanks funded by government have become important assets for top universities in Moscow and St Petersburg in the last decade but are also very vulnerable to changing political circumstances at the very top of government. At a lower level, humanities research has been useful for governors across Russia when they apply for funding to generate foreign tourism. On the other hand, there are very high-profile cases of academics working with journalists and the public to prevent the destruction of historical sites.

African interviewee Af4 deplored

the striking disconnect between researchers and policy makers. In fact, they are rivals and do work at cross purposes. This is a tragedy as much useful research findings end up in the garbage bin or on the idle shelf. Civil servants often see academics as threats and do not understand why they should be better paid or funded.

However, some parts of the humanities in Africa do get the attention of government. Af7 mentioned that 'the latest institution to come up with a research unit is the Zambia Police Service. The researchers are engaged to conduct research in the field of security and facilitating 
the operations of the Police Service.' Af11 was called on to translate historical documents in indigenous languages into English to settle a dispute.

While many Western European academics did have a role in politics, it is striking that few identified a direct political role for the humanities. E9 was the most explicit:

One of the research themes of our institute is about the academic and the civic, about how universities have an impact on and are impacted by their local communities. As for public policy, networking tends to be very much a social science thing, though they hold meetings at the Institute. But on our advisory board we do have civil servants....

Such a role was also identified for leading humanities academics in Estonia (E7):

Quite many members of our faculty belong to various decisionmaking bodies on national level (a big university in a small country). Many of us are members in different academic societies, belong to advisory boards at different ministries, etc..

A more negative view was that of $\mathrm{E} 4$ who saw a contradiction between translation in a broad sense and that of policy advice. While the interviewee personally believed strongly in the usefulness of broad outreach, most colleagues thought that 'the only acceptable form of translation would be influencing public policy makers (the contemporary equivalent of advising the King). Anything else is considered vulgar.'

North American and Asian scholars rarely mentioned a policy role for the humanities. One respondent from Taiwan (As7) mentioned that some scholars have a direct role in political life, but added that they tend to be drawn from the social sciences. NA10 stated that policy advice was a potential role for non-academics: 'The non-profit researchers we work with may have policy recommendations [and] they may work with our faculty to come up with those.'

\section{Engagement with businesses and the innovation system}

Humanistic entrepreneurship was mentioned specifically by only four people, two of them stated that it rarely happens, the two positive comments were from Chinese respondents. As16 mentioned that his 
department ran a programme every year for business entrepreneurs and most members of the department participated. It regularly attracted about 30-40 people, mostly senior businessmen. As11 stated that the best use of philosophy was by philosophers in the medical school working on bioethics (e.g. regarding stem cell research).

However, E13 may have reflected a more general view by stating that 'the humanities haven't really cracked open the business sector'. In a more negative sense, this is confirmed by $\mathrm{E} 4$ who stated that her university 'has a knowledge transfer office, but its Director only considers translation in a neo-liberal way. He has no time for the hardcore humanities (only the digital humanities). ${ }^{6}$

One respondent emphasised the benefits of working closely with private benefactors and the public support system for innovation:

$A u 2$ : Our organisation is very actively concerned with stakeholders outside of the university, to a degree that in the humanities it would be very unusual in Australia. It's a specific policy of ours and it's something that we have decided we want to do. And it's also been influenced by the fact that these grants that I've been getting through the government system of these linkage grants, which are with industry partners, have proved to be so much more gettable and so much better value for money and so much more fluid in terms of open to open-minded research that we use that as a model in my particular institution as a desirable thing. And it's also true that we have one or two quite significant business patriots who are loyal to us and work with us and help us in that way.

\section{Engagement with public institutions}

Collaboration between humanities and arts practice was emphasised in interviews with UK academics. E12 stated that 'there are numerous collaborations between members of the school and non-academic stakeholders, from links between our creative writers and theatres, book festivals and publishers' and went on to give examples of working with other public and private parties. E9 similarly reported 'very active creative partnerships' with galleries, cinemas and an international arts festival.

An Australian view (Au1, already quoted) was that 'a lot depends on your field; the fine arts do well with galleries and museums, as do local historians to an extent. But international historians are less out there (except on radio and occasionally TV).' Russian interviewee R3 reported that 
we are developing cooperation with the museum in honour of Astafev where a part of the heritage of the writer is being preserved. Fellow linguists are studying the language of indigenous peoples of Siberia, corpus linguistics with the help of dialect material (the language of the indigenous population of Siberia), the latest initiative is supported by the fund in honour of Prokhorov and the regional museum.

During the Russian workshop several examples were given of Moscow art galleries working with academics to develop educational platforms and organise cultural events. African respondent Af11 had been invited by the management of museums to hold seminars, which in turn helped in the running of the establishment.

\section{Conclusion}

Our interviews and workshops brought out that humanists engage with the world in many ways beyond the traditional academic practices of teaching and scholarly publication. However, most examples concerned a one-way rather than a two-way communication of knowledge, thus not very often being truly translational. Furthermore, it is clear that much of this activity depended on the individual and that very little institutional support was in place. Indeed, many colleagues will be sceptical or even disdainful about such practices and it is unlikely that time invested in translation is matched by career progress. As a concept translational humanities may benefit from the insights of translational medicine, but in practice the two are worlds apart. Perhaps As13's response summarises the sentiment of those who take a positive view of translational practice:

When it comes to translation, I feel like a sacrificial lamb. I have to sacrifice my own research. It's time consuming. It's difficult to create a team and sustain it. It does not benefit my research career but it does give me a sense of pride.

\section{Evidence from national reports}

We have found relatively few national reports on translational humanities - or on any subset of this phenomenon. While funding agencies, ministries and councils are concerned with how and why they spend their money and therefore report on humanities research objectives, they are much less inclined to investigate the translation and use of 
the knowledge produced. Questions of translation may get a fleeting treatment but reports rarely provide data that lend themselves to wider comparison. We limited ourselves therefore to those few reports from North America and Africa that did provide a baseline for future comparative study.

\section{United States}

The Association of American Universities (AAU) conducted a survey of outreach activities in 2002, published in 2004 as part of a more general report. ${ }^{7}$ This survey is clearly dated but remains the most comprehensive source available. It looked at the outreach activities of over 40 universities. In 2012, in an effort to update the information, we revisited the websites of the universities concerned to see if the outreach activities were still ongoing and in what ways they had developed. Outreach was clearly a different concept from the translational model that we prefer and may be used only as a proxy for those translational activities that deal with dissemination and some exchange activities.

It is useful to look at an example of outreach in the US context to see how the concept is defined. At Ohio State outreach and engagement are defined as meaningful and mutually beneficial collaborations with partners outside the academic community, such as those in education, business, and public and social service. The university identified outreach and engagement as:

- That aspect of teaching that enables learning beyond the campus walls

- That aspect of research that makes what we discover useful beyond the academic community

- That aspect of service that directly benefits the public.

This definition puts the emphasis on teaching services to the community. Knowledge transfer rather than knowledge exchange is clearly identified as the primary function. A similar picture emerges from the responses by the $40+$ universities that informed the report. They framed the activities in terms of: publicising the humanities; involvement with policy; outreach to K-12 schools; collaboration with state humanities councils; and outreach efforts to the community. Most of the activities identified were public lectures, adult education and broad arts programmes, while other outreach activities were festivals, TV and other media services, writers' workshops seminars and community engagement. Only a couple of universities identified involvement with 
policy development and human rights. The liberal education focus led to an emphasis on outreach to high schools in US; and outreach to K-12 schools (upper secondary level preparing for university) was identified by many universities.

University faculties in the US are generally evaluated on research, teaching and service, often based on a roughly 40-40-20 split. While about a third of the AAU universities considered outreach activities only minimally or informally, others had increased the recognition given to such efforts and viewed them as important. Even among the latter it remained clear that those efforts would not, by themselves, lead to tenure. Research, publication and teaching remained the primary criteria upon which tenure was based. Moreover, although most universities considered outreach projects as a part of the service component, this was not universally true. A few AAU universities still construed service primarily as service to the academic community. Outreach programmes, however, can do a great deal to communicate the value of the humanities (and of the institution) to the surrounding community. Finally, it appeared that most outreach activities were conducted by tenured faculty. Indeed, one university specifically discouraged junior faculty from outreach activities in order to give them time to establish themselves in their disciplines. At that institution, senior faculty led each of the university's major humanities outreach initiatives and were rewarded for their efforts through pay.

\section{Africa}

In March 2009, the British Academy published a report about research collaboration in the SSH between the UK and Africa. ${ }^{8}$ It was described as 'the culmination of a two-year process of reflection and discussion among UK and African scholars across the humanities and social sciences' and presented 'a series of frameworks derived from the collective ideas of some 60 scholars and research leaders, who met in Nairobi in September 2008, which aim to address the challenges facing Africa-UK research collaborations in the humanities and the social sciences, and to formulate practical solutions to these'.

In general, the report argued that many of the barriers to research were organisational and managerial rather than simply financial. New money for research was only provided if there was confidence in the ability of institutions to manage it and to deliver good research. In this context, questions of translational research practices are important for the future development of a healthy research environment in the humanities.

The issue of translation featured in the report in two ways. First, in many African universities there was often little or no time allocated 
to research and any research or writing had to be squeezed out of a researcher's own time. Rates of publication were therefore currently low across the continent, and the report found that early career researchers needed support and advice to negotiate the peer review and publishing chain. But it also found that they needed support to understand how to communicate their research beyond the academic world. In advocating the need to develop platforms for public engagement and discussion, it argued that departments and research networks can do much to support this by hosting public discussions of research and through encouraging scholars to write for newspapers and non-scholarly publications, online and offline, with due recognition for this work.

The second reference to translational research in the report concerned academic consultancy. It was interesting that in some African countries, scholars in the SSH were able to do consultancy work. In one sense this was a success story from the translational side of things. But, according to the Report, this phenomenon also gave rise to concerns, because such work was not done for the benefit of the university to which the scholar belongs, but 'on the side'. So the report recommended that African universities seek to incorporate consultancy formally within departmental research programmes to encourage academics to contract their expertise through their institutions rather than independently. Research management offices might be a way to further such a process.

\section{Canada and the UK}

Chapter 2 brought out that few academics would argue the case for the humanities on the grounds of their economic contribution to society, and this chapter confirms that very few mention academic interaction with businesses and the innovation system as part of their translational practice. Yet, there is solid ground for arguing that the humanities contribute in a major way to the economic wealth of modern society. If this is correct, we are faced with major questions as to why academics do not perceive their role in this way and how, despite their lack of engagement, they nevertheless play a major role.

The research councils of the United Kingdom have taken a lead in recent years to advocate and measure the impact of research in broad societal terms. However, in 2008 Research Councils UK decided to abandon its effort to develop a universal algorithm to calculate the economic impact of all types of research, because of the difficulty of the task. Later reports on the societal benefits of humanities indicated that, while it is comparatively easy to measure effort (outreach and other translational measures), it is exceedingly difficult to measure impact. 
In 2008 the Impact Group of the Canadian Social Sciences and Humanities Research Council published a report on the economic role and influence of the social sciences and humanities. The report concluded that

academic knowledge - whether from SSH or STEM - is not a principal input to the economy - or at least not a direct input to the economy. Yet, [...] embodied knowledge (technology) and tacit knowledge (know-how) are all important inputs to enterprises. The discrepancy, if any, we believe is due to the fact that 'raw knowledge' knowledge that arises directly from research - does not become useful to business enterprises until it is expressed through publications/conferences, technology, or people (employees, consultants, etc.). The fact that enterprises tend not to use 'raw knowledge' as it comes directly from academe, should not be confused with the fact that the same knowledge can be of immense value when it reaches enterprises through other sources, often when those sources (e.g. students, consultants) have added value to the raw knowledge. ${ }^{9}$

This line of reasoning highlights the importance of understanding what goes on when research is translated. Unfortunately, the report goes on to say: "This discussion highlights the importance of so-called "knowledge transfer" activities in an academic setting, a topic that is beyond the scope of this paper' (p 32).

Despite the difficulties the report made a bold general assessment of the economic value of STEM and SSH to Canadian industries and concluded that, while STEM are of very high importance to the GDP of the goods sector, the economic value of SSH to the services sector is of the same magnitude. A similar conclusion was reached by a study of the value of STEM and SSH graduates to the goods and services sectors in Denmark ${ }^{10}$ and an analysis of the careers of Oxford University graduates reached a similar conclusion. ${ }^{11}$ In the US some useful data has been collected on the employment of humanities graduates. ${ }^{12}$

While these results are interesting, they highlight the need to understand what actually goes on when academic research is translated to wider use - not only for economic but also of social and cultural value. The Canadian report notes that

vast parts of our economy are in the business of creating or trading in products and services that rely directly on the social sciences and humanities, or are otherwise essentially SSH in nature. About 
two-thirds of all industry sectors can be described as 'SSH industries' industries whose primary knowledge input comes from the SSH or that sell SSH-based services (e.g. banking) or goods (e.g. television programs). And, SSH industries employ about three-quarters of all workers. [...] And yet, there is virtually no literature on the economic role and influence of SSH. It should therefore not surprise us that to date, public policy has devoted little attention to the importance of SSH for innovation and competitiveness.

\section{Other evidence}

There is much evidence for exemplary translational humanities that we have not been able to draw on for this report. The humanities are fortunate to have a large number of outstanding communicators. Anyone doubting the value of seemingly exotic topics should be persuaded by TV ratings that the humanities certainly have a large audience.

The humanities are inventing new ways of communicating with the public and politicians. The annual summer Swedish gathering of researchers and politicians in Almedalen, Gotland, is a great example of how new ways of interaction may help accelerate knowledge exchange in a radical and very direct way - and with close media attention. ${ }^{13}$

New ways of training humanities graduates are being tried out. The Danish industrial $\mathrm{PhD}$ programme, which allows humanities graduates to combine university research with practice-based learning in private companies, is a model that is now being introduced in other European countries and at the EU level. ${ }^{14}$ In many cities new ways of grassroots engagement with humanities scholars are being played out - ranging from Ignite sessions, which force scholars to present their research in entertaining and flashy ways, to academic engagement with urban communities who are not usually exposed to academia, such as the Irish DublIntellectial. ${ }^{15}$

\section{Conclusion}

Observations about translational research practice are of relevance not only to the study of large research teams with considerable division of labour and substantial funding, but they are also important for understanding the role of academics working on their own, the lone scholar model, with no more institutional support than a salary, writing tools 
and a library. Of course, some humanists may choose to largely disregard questions of translation and simply write papers and books for an anonymous market. On the other hand, many others do think carefully about the use and distribution of their knowledge and by so doing reflect on their translational practice.

In this chapter we used various sources to get a glimpse of the wide variety of translational practices that happen in the humanities, and we discussed some of the problems involved. In the end these can be boiled down to two.

The first is one of practicalities. The humanities seldom have the financial overheads to pay for transaction costs. A humanities scholar typically needs to cover all the roles of basic scientist, entrepreneur, fundraiser, communicator, activist and lobbyist. If you are not able to play all parts, it is likely that your research will have less impact, therefore translational practices are of utmost importance to senior academics. However, translation may be a drain on academic energy and acuity. Too much focus on translation may have a damaging impact on the junior researcher who needs to build an academic career on the basis of their own research contributions before they start engaging in translation.

The second problem concerns academic integrity. Researchers involved in translation need to strike a balance between being sensitive to the knowledge needs and expectations of the user and sufficiently insulating their research from prescriptions at the receiving end. The former implies the need for channels of communication between researchers and end users. This necessarily exposes the research to a feedback loop, which may impact the design and possibly the outcome of the research itself. It is therefore of the utmost importance to identify and develop checks and balances in the research process to limit bias.

So, while there may be substantial funding benefits to researchers, who have an eye on translational practice, there are inherent dangers as well, which may divert attention or, in the worst case, compromise the research itself.

A full understanding of translational research practice involves sensitivity to risks and opportunities from academic management and researchers. There are real dangers of goal conflict, which need to be borne in mind. Management may need to implement smart sanctions to encourage well-functioning translational practices. If we agree that the humanities may provide socially valuable knowledge, questions of academic freedom of ethics follow. Such questions are often overlooked 
but need to be more directly addressed in any evaluation of humanities research practice. The solution is not to abandon translational practices. Society already suffers huge opportunity costs by not developing translational humanities. That is, the humanities represent an enormous knowledge pool that today is tapped only in haphazard and entirely contingent ways.

Except where otherwise noted, this work is licensed under a

Creative Commons Attribution 3.0 Unported License. To view a copy of this license, visit http://creativecommons.org/licenses/by/3.0/ 